\title{
A estética da identificação comunicacional a dimensão sensível territorial na feira do Guamá, Belém - PA
}

\section{The aesthetics of communicational identification the territorial dimension sensitive of the Guamá market, Belém-PA (Amazon)}

\section{Fábio Rodrigo de Moraes Xavier*}

\section{Resumo}

Neste artigo, nós apresentamos reflexốes acerca da estética da identificação comunicacional e a dimensão sensível territorial na feira do Guamá, localizada em Belém - PA, situada na Amazônia brasileira. Procuramos observar, por meio do processo etnográfico, a sensibilidade interacional, apresentando a ideia da estética da identificação, a maneira como ocorre o processo de interação e a dimensão sensível territorial, assim como o modo como as vivências e as emoções se expressam na localidade. Discutimos a expressividade estética com percepção à condição espacial temporal da realidade ali observada, bem como o aspecto sensível do lugar, isto é, a feira, que tem como essência o sentir em comum, a arte de viver.

Palavras-chave: Comunicação; Estética; Território; Arte; Feira.

\begin{abstract}
In this research we analyze the aesthetics of communicational identification and the territorial sensible dimension in the market of Cuamá, located in Belém - PA, within the Brazilian Amazon. Using the ethnographic process, we tried to observe an international sensibility, presenting the notion of aesthetics of identification, how theinteraction process occurs and how the territorial sensible dimension, as well as experiences and emotions express themselves in this location. We discussed the aesthetic expressiveness perceiving the spatial and temporal condition of the observed reality, as well as the sensible aspect of the place, that is, the market, whose essence is the common experience, the art of living.
\end{abstract}

Keywords: Communication; Aesthetics;

Territory; Art; Market.

\footnotetext{
* Mestrando no Programa de Pós-Graduação em Comunicação, Cultura e Amazônia da Universidade Federal do Pará e graduado em Comunicação pela mesma instituição. Participou do projeto de pesquisa "Experiência social, cultura e comunicação na Amazônia. Etapa 1: intersubjetividade e pragmática comunicativa em mercados de Belém". Email:fabio.rodrigo.moraes. xavier@gmail.com
} 


\section{Artigos e Ensaios}
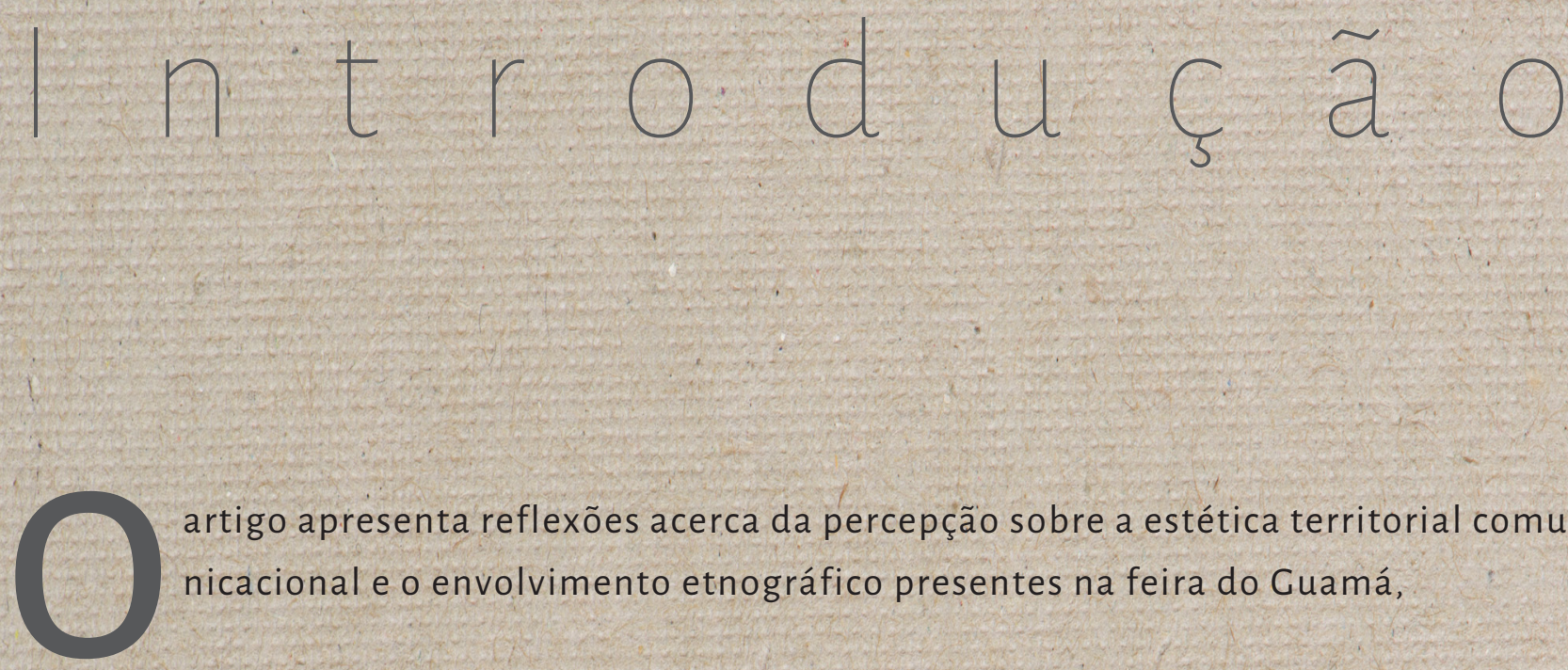

artigo apresenta reflexões acerca da percepção sobre a estética territorial comunicacional e o envolvimento etnográfico presentes na feira do Cuamá,

A feira municipal do Guamá localiza-se no cruzamento entre a Rua Barão de Igarapé-Miri e a Avenida José Bonifácio, no bairro do Guamá, em Belém, capital do Pará. Possui movimentação e influência na economia local, bem como na estruturação social do bairro e dos bairros limítrofes. Trata-se de um espaço convencional de comercialização de produtos, dedicado à venda de frutas, legumes, carne, pescados, farinhas, ervas medicinais tradicionais, e produtos industrializados convencionais. (CASTRO, XAVIER; CASTRO, 2017, p. 363)

A localidade encontra-se na periferia de Belém e nasce nos meados do século XIX por causa da extensão de uma linha de bonde.

O burgo do Guamá, bairro popular de Belém, se consolidou em meados do século XIX e ao final desse foi atendido por uma linha de bonde. Destinada a se encerrar em Santa Isabel, espaço de um cemitério dezenoviano já então populoso, a linha se estendeu até um pouco mais à frente e em seu ponto final se formou feira que lá hoje há. (CASTRO; CASTRO, 2017, p. 3)

O objetivo de investigação na feira é fazer uma reflexão tendo como ideia o entendimento da estética da identificação e como se desenvolve a dimensão sensível territorial na essência interacional entre os sujeitos deste local. Pretende-se identificar a composição de como ocorre o processo de interação comunicacional que se evidencia na relação dos frequentadores e na formatação da realidade espacial temporal ali expressa, isto é, a percepção da arte da vivência.

A indagação central diz respeito tanto à estética da identificação quanto à dimensão sensível territorial na Feira do Guamá, para assim termos ideia de como ocorrem a comunicação e a percepção da cultura e da sociedade. Busca-se perceber o sentimento em comum como fator de estruturação socio-cultural, como essência da interação entre os sujeitos presentes quotidianamente na localidade.

Para alcançar este intuito, baseamo-nos em Maffesoli $(1998,1999)$, que desenvolve os conceitos de percepção do universo simbólico comunicacional e reflexão estética. Também com- 
partilhamos a ideia de identidade proposta por Hall (1999), o qual discorre sobre a construção dinâmica na sociedade. Estes autores nos possibilitam propor uma reflexão sobre a realidade que o local representa e como demonstra a sensibilidade.

No que concerne à dimensão sensível territorial, Haesbert $(2004,2007)$ aborda a observação territorial e a condição de construção que se expressam na realidade ali existente. Há contribuições igualmente importantes de Guattari e Rolnik (1986) para as noções de movimentação e desterritorialização.

Nós podemos, então, entender a colocação da estética da identificação como formatação da realidade, assim como no processo de realização de sensibilidade produzida no local em determinado tempo espacial. Pode-se assim adentrar no desenvolvimento e no envolvimento da territorialidade, tendo como base a comunicação e a interação existentes entre as pessoas que frequentam a localidade.

as feiras por serem locais que carregam trajetórias, relíquias do passado, singularidades, crenças, tradições, costumes e identidades de um grupo. Constituem-se como espaços onde ainda é possível respirar, sentir, tocar e ver o "coração" de uma cultura. (LOBATO; CAÑETE, 2015, p. 242)

O estudo que aqui propomos se desenvolve na percepção da identificação de como ocorre a sensibilidade e como proporciona o desenvolvimento territorial em um tempo existente na feira. Nós buscamos entender as condições para o entendimento do sujeito amazônico, bem como a movimentação e a noção da cultura da sociedade, a comunicação, o ser Amazônia.

O procedimento para a efetivação da pesquisa baseia-se na reflexão teórica sobre a temática e em visitas realizadas na feira do Cuamá (etnografia), com a utilização de material para a coleta de dados. Isso possibilitou o conhecimento sobre o funcionamento das expressividades dos frequentadores que estavam presentes no lugar e na composição estética, incluindo a identificação comunicacional e a dimensão sensível territorial.

\section{A estética da identificação comunicacional}

A reflexão sobre o desenvolvimento do lugar e a expressão estética da identificação encontra-se no espaço em um universo simbólico que "é preciso compreender como sendo a soma de interações que constituem, essencialmente, a vida social" (MAFFESOLI, 1998, p. 123), para que assim 
possamos ter uma reflexão de como ocorre a formatação da realidade social ali constituída, dentro de um processo de sensibilidade interacional, comunicacional.

Nós temos como horizonte Stuart Hall (1999), teórico que propõe três concepções de identida-1 de. A primeira é a do sujeito iluminismo, em que figura o entendimento do indivíduo centrado, unificado, dotado de capacidades da razão. Como se aquele sujeito tivesse um processo de identificação estático, consistindo em um núcleo interior que emerge e se desenvolve, permanecendo a mesma essência.

A segunda concepção é a de um sujeito sociológico, cuja complexidade é determinada na realidade de um mundo moderno. A percepção de indivíduo não autônomo haveria de ter relação com o outro que se identifica, para a mediação de valores, sentido, símbolos, preenchendo um espaço temporal entre o mundo "interior" e "exterior", entre o mundo pessoal e o público.

Pode-se perceber a contribuição de posicionar sentimento subjetivo com lugares objetivos que cada indivíduo ocupa em um mundo comunicacional, cultural e social. Como se a identificação fosse algo que se compõe de textura para a construção do indivíduo em determinada estrutura de formatação de realidade.

A última percepção refere-se ao sujeito pós-moderno, caracterizado como aquele indivíduo que tem uma identidade instável, fragmentada, ou seja, em movimento. Muitas vezes, com várias identidades, algumas podendo ser contraditórias e não resolvidas, problemáticas, desta forma, compondo um campo de formatação do real, como uma espécie de múltiplos territórios sensíveis.

Argumenta-se, entretanto que são exatamente essas coisas que agora estão "mudando". 0 sujeito, previamente vivido como tendo uma identidade unificada e estável, está se tornando fragmentado; composto não de uma única, mas de várias identidades, algumas vezes contraditórias ou não resolvidas. Correspondentemente, as identidades, que compunham as paisagens sociais. "lá fora" e que asseguravam nossa conformidade subjetiva com as "necessidades" objetivas da cultura, estão entrando em colapso, como resultado de mudanças estruturais e institucionais. O próprio processo de identificação, através do qual nos projetamos em nossas identidades culturais, tornou-se mais provisório, variável e problemático. (HALL, 1999, p. 12)

Notamos assim certa argumentação sobre o processo da realidade, formado por determinado indivíduo, como algo que se estrutura em sua diversidade de sentido e composição na construção de sensibilidade comunicacional. No local é possível perceber, no que concerne ao modo de divisão dos boxes, assim como no processo da interação entre os frequentadores, cheiro, higiene, a sonoridade e o envolvimento dos feirantes com os fregueses. 

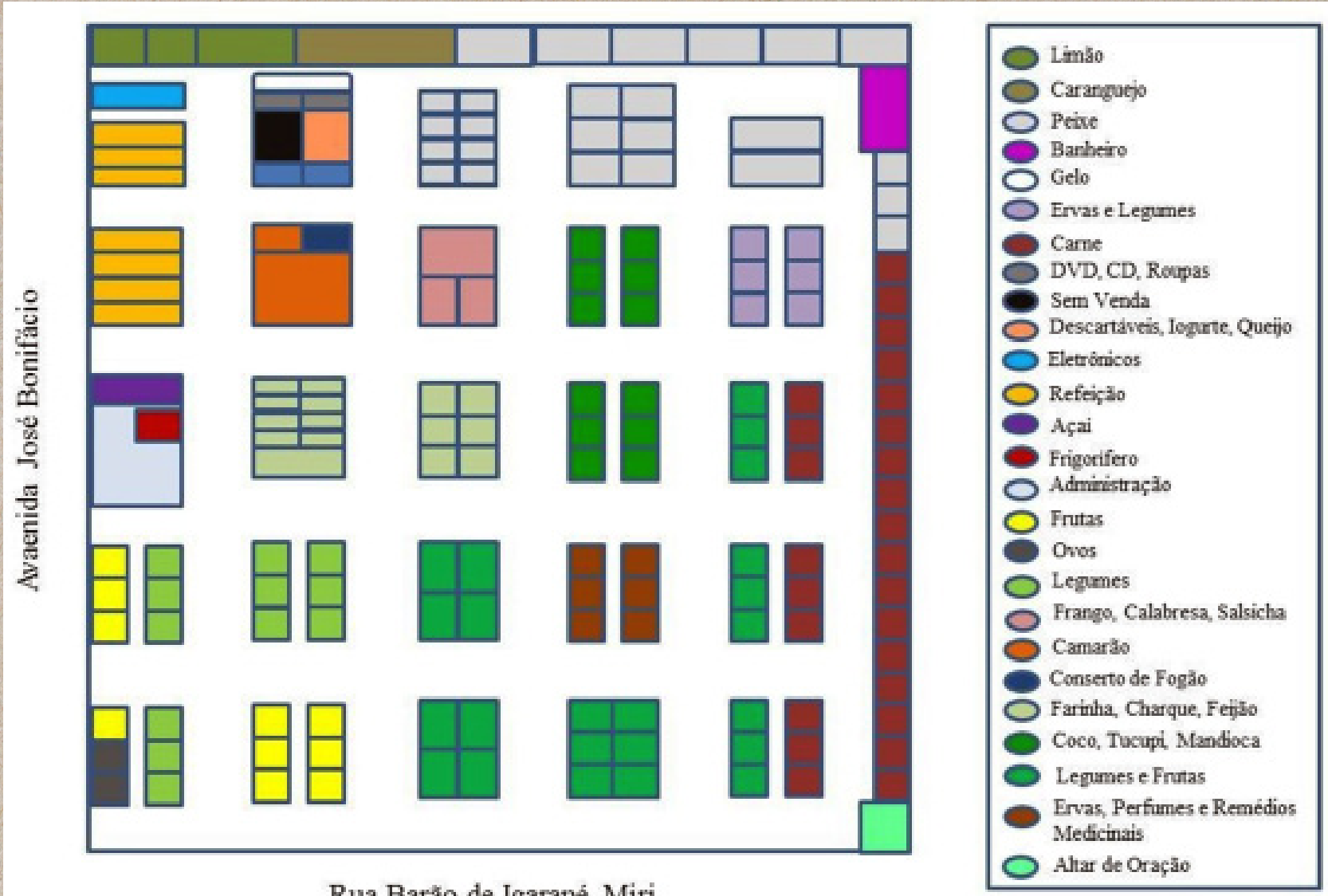

Rua Barăo de Igarapé Miri

Fonte: Elaborada pelo autor.

No processo de instituição do movimento de identificações que ali se encontra em desenvolvimento, percebemos que: "É, portanto, a partir de uma arte generalizada que se pode compreender a estética como faculdade de sentir em comum" (MAFFESOLI, 1999, p. 28). A prática social, a movimentação da feira e a ligação entre os feirantes revelam diversos fatores construtivos da interação, ressaltam uma ética da estética, um prazer, desejo de estar-junto.

O próprio cumprimento entre os feirantes, como também o envolvimento com o seu freguês, condicionam a relação de prazer, isso pode posicionar uma melhor constituição de sentimentos que ali se evidenciam. Nós temos como exemplo expressões como "minha freguesa", "hoje o charque tá magro", "tá barato hoje", "tá só o creme" - retratos de como o posicionamento simbólico pode corroborar para um melhor grau de aproximação e identificação sensível.

No primeiro momento, isto poderia ser insignificante, mas propõe certa relação simbólica da construção de relacionamento. Então, "está renascendo uma outra concepção do tempo que vai privilegiar o que os romanos chamavam de otium, uma espécie de férias, ou melhor, da 
disponibilidade social, que deseja compor o lazer, a criação, o prazer de estar junto" (MAFFESOLI, 1999, p. 66). Como se aquele processo de venda estivesse, de algum modo, composto de assentamento de disponibilidade e de sentimento, algo que se caracteriza tanto na própria formação espacial-temporal quanto na dimensão estética que ali são evidenciadas.

Na fala do feirante a seguir, é importante perceber a reflexão do processo de construção conjunta da estética da identificação, a partir do processo de experiência que ali está envolvido para o procedimento de determinado contato de interação.

A gente joga bola aqui aí na arena do farinhão no futevôlei. Aqui tem clube todo ano tem campeonato, quatro clube aqui, aí disputa lá na arena, quem é campeão ganha um dinheirinho, faz a festa. O feirante tem essa virtude que, me dá um real me dá dois aí me dá cinco aí pra fazer isso aqui, cara dá, corre dinheiro, por isso que fico na feira, não tem melhor lugar do mundo pra viver como feirante, tem dinheiro toda hora todo dia, alguns dias falha, mas melhor lugar. (OLIVEIRA, 2017)'

O discurso do vendedor colabora para a construção de laços de prazeres, bem como para a socialização entre eles. A feira tem quatro times de futebol que se reúnem para fazer um campeonato, que, normalmente, ocorre no final de ano - um tipo de confraternização que desencadeia o desenvolvimento da reciprocidade e maior interação entre os indivíduos.

A troca de dinheiro também faz parte da caracterização do que ocorre naquele momento para o movimento festivo. Nós podemos observar que chega a certo altruísmo, como se fossem "colecionadores de experiência e sensações" (FRIDMAN, 2000, p. 80). A condição de que a localidade se transforma no melhor lugar do mundo, evidenciando a dimensão estética da identificação, mostra-se na carga de diversas emoções que aquele feirante possui em sua memória.

Portanto, é perceptível que "experimentar junto emoções, participar do mesmo ambiente, comungar dos mesmos valores, perder-se, numa teatralidade geral, permitindo, assim, a todos esses elementos que fazem a superfície das coisas e das pessoas fazer sentido" (MAFFESOLI, 1999, p.86) constitui determinada formatação da dimensão estética, com o envolvimento das pessoas que compartilham naquele lugar o ato de sentir em comum, a arte de viver.

A estética da identidade é desenvolvida dentro das variações e nas trocas simbólicas expressas ali, ocorrendo entre os sujeitos, forma pela qual acompanha a prática, ó movimento e a formatação da dimensão estética. Deste modo, é possível perceber que influencia no modo da representação desenvolvida naquela realidade.

1 Mário de Oliveira vende charque que é uma carne bovina salgada cortada em mantas e seca ao sol em muitos preparos. Esse produto é utilizado, muitas vezes, para dar gosto ao feijão e também é consumido frito para ser saboreado junto com o açaí em polpa. 
O importante são as representações que os indivíduos fazem da realidade social e de suas divisões. (...) A construção da identidade se faz no interior de contextos sociais que determinam a posição dos agentes e por isso mesmo orientam suas representações e suas escolhas. (...) Devese considerar que a identidade se constrói e se reconstrói constantemente no interior das trocas sociais. (CUCHE, 1999, p. 182-183)

A prática e o movimento compõem a estrutura de envolvimento na própria conciliação da essência do que ali é representado, condicionado e formado. De maneira direta, na perspectiva simbólica do pensamento, encadeia o modo como as pessoas ali interagem.

Neste sentido, a construção da relação entre os feirantes é alicerce para o posicionamento da formatação que determinados sujeitos expressam no local. O posicionamento que possui cada indivíduo ali estabelece novas perspectivas de pensamento e desenvolvimento da capacidade normativa de fatos, o que é desenvolvido e como abrange as pessoas que participam da feira.

É possível observar, na prática da venda e na aproximação do freguês, a expressividade que cada feirante possui na formatação da representação e na disposição entre os sujeitos que frequentam o lugar. Confirma o processo de ordenamento simbólico, que solidifica a base para o envolvimento da estética da identificação comunicacional.

Sendo também alicerce de formatação de posicionamento, o contexto sensível proporciona, de algum modo, influências sobre a maneira pela qual ocorrem as interações. 0 envolvimento que as pessoas ali desenvolvem ocasiona 0 resultado da capacidade de identificação e de ser identificado.

Imagem 2 - Placa do local onde ocorre a venda da farinha. Belém-PA (2017)

A sensibilização envolve certo contexto de construção simbólica que está, de algum modo, evidente na ideia do lugar. Nós podemos entender que "o lugar é aquele em que o indivíduo se encontra ambientado, no qual está integrado. O lugar não é toda e qualquer localidade, mas aquela que tem significância afetiva para uma pessoa ou grupo de pessoas" (COSTA; ROCHA, 2010, p.37).

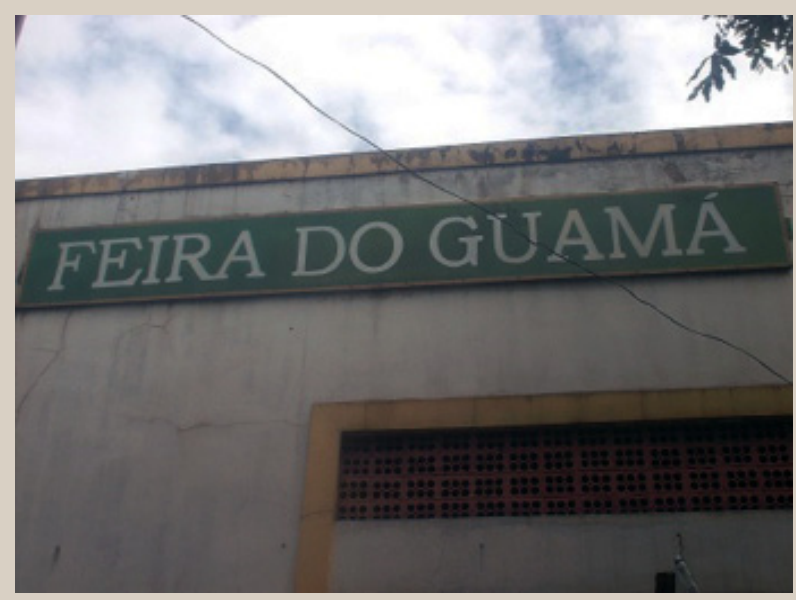

Fonte: Elaborada pelo autor.

Quando alguém chega e faz algum tipo de saudação para aproximação do outro, isto é, algum procedimento para interação, nós temos a expressão da localidade. Podemos ter como 
exemplo a disponibilidade do feirante para o freguês, a exemplo da fala: "chegou a minha freguesa", "olá baroa", o inverso também ocorre, "quero bem magro" "quero promoção em", que se caracterizam como pontos de alicerce da efetivação e da integração do lugar, bem como a formatação da ambientação temporal, do que a localidade é.

Na feira, entre os próprios feirantes, o processo do lugar combina a efetivação do modo de integração e a harmonia para o procedimento de venda do dia. É importante observar que as barracas dos produtos se localizam uma ao lado da outra, são divididas em setores, como exemplo: peixe, legumes e frutas, refeição. Esta organização serve para facilitar a entrada dos fregueses para a efetivação da compra, colabora para a sensibilização e para o processo de ambientação que forma e desenvolve a construção da identificação estética e a significância afetiva para determinado grupo social.

Em alguns momentos, a maneira como está disposta a barraca também pode ocasionar rivalidade entre os feirantes, porém não tem tanta relevância para o procedimento da compra e de vivência da feira, pois, na maioria dos casos, ocasiona malefícios para a venda, como se eles estivessem trabalhando conjuntamente para a sobrevivência. Algo que é característico dentro desta ideia é o valor dos produtos, visto que, muitas vezes, as barracas utilizam o mesmo valor para o mesmo produto.

Dentro deste processo, nós podemos ter o entendimento de que as condições da dimensão estética da identidade são características do modo de vivência ali submetido. Demonstra-se como um processo que, a cada dia, vai se movimentando pela construção estética expressiva, proporciona a formatação da realidade presente.

Assim, a identidade é realmente algo formado, ao longo do tempo, através de processos inconscientes, e não algo inato, existente na consciência no momento do nascimento. Existe sempre algo "imaginário" ou fantasiado sobre sua unidade. Ela'permanece sempre incompleta, está sempre "processo", sempre "sendo formada." (HALL, 1999, p.8)

Pode-se entender que a identificação, em seu tempo, constitui uma caracterização da sensibilização e é também ponto norteador de formação de interações. Deste modo, a identidade se encontra de maneira íntima com a própria constituição da estética, modo formatador da realidade que é condicionada, como se fosse um processo de experiência vivido dentro da realidade simbólica em movimento da localidade.

O aspecto imaginário associa a perspectiva de se obter algo para a construção do modo imagético que é criado no movimento do cotidiano. Em vista disso, condiciona representações que 
permanecem como fonte de propagação de ideias que são formadas na comunicação, entre sujeitos, indivíduos em envolvimento com o grupo social em determinado tempo de ser.

Pode-se notar que o aspecto da identificação colabora para a base do fator territorial sensível e para o envolvimento da formatação da sensibilidade territorial pelo processo simbólico que encadeia as ideias entre pessoas que frequentam o local e forma realidades. Este fato proporciona a condição de vivência que, na feira, também comporta a construção do real ali envolvido no processo territorial sensível.

\section{A dimensão sensível territorial}

No que tange à dimensão sensível territorial, ela ocorre na localidade pela via da expressividade, pois consiste em um processo de movimentação simbólica, cujo envolvimento comunicacional de relações evidencia-se na interação do cotidiano. Logo, temos aqui, como ideia, de que é algo passageiro, fugaz, em que as identificações territoriais se constroem na realidade e influenciam a perspectiva de ser dos sujeitos que frequentam a localidade.

Assim, no que estamos denominando aqui de identidades territoriais, escolhem-se (ou concomitantemente reconstroem se) espaços e tempos, geografias e histórias para moldar uma identidade, de modo que os habitantes de um determinado território se reconhecem, de alguma forma, como participantes de um espaço e de uma sociedade comum. (HAESBAERT, 2007, p. 44)

A denominação identificações territoriais possui atrelamento ao processo espacial e temporal como fonte de expressividade e sensibilidade da localização. Evidencia a forma de sensibilização que ali é expressa, como modo de reconhecimento, a arte de viver, o sentir em comum das pessoas que desenvolvem a formatação da realidade da feira.

Nesse caso, caracteriza-se como fonte estética que promove o procedimento da experiência do ambiente. Os participantes daquele processo de interação possibilitam o modo de reconhecimento e construção da forma de adequação para o desenvolvimento do espaço simbólico, pela via da intersubjetividade (SCHUTZ, 2012), transformando-se em uma construção comum, comunicacional, social e cultural.

A dimensão estética territorial sensível cabe na percepção dessas forças expressas na feira, na forma de propor melhor interação em certo tempo e também no envolvimento de fontes de poder no espaço simbólico, na realidade, no cotidiano ali presente. 
Portanto, todo território é, ao mesmo tempo e obrigatoriamente, em diferentes combinações, funcional e simbólico, pois exercemos domínio sobre o espaço tanto para realizar "funções" quanto para produzir "significados". O território é funcional a começar pelo território como recurso, seja como proteção ou abrigo "lar" para o nosso repouso, seja como fonte de "recursos, naturais" - "matérias-primas" que variam em importância de acordo com o(s) de sociedade(s) vigente(s). (HAESBAERT, 2004, p.3)

O aspecto funcional simbólico das diferentes combinações inclui a maneira como o espaço é desenvolvido e também abarca o molde social que pode ser caracterizado por diferentes modos interacionais temporais. Pode caracterizar-se na própria formatação da construção simbólica, assim como abriga relações de venda, matéria-prima para obtenção de lucro e recurso de disponibilidade de produtos que estão dispostos.

Podemos, então, ter a reflexão Imagem 3 - A venda de farinha tapioca. Belém - PA (2017)

da feira como forma, pensar em possibilidades de comunicação e construção que cabem no processo simbólico. Como podemos observar, a sensibilidade ocasiona a formatação da localidade, evidenciando o envolvimento entre os frequentadores.

Assim adentramos a cultura dos sentimentos que é fator motriz para a adequação de produtividades. À guisa de exemplo, o

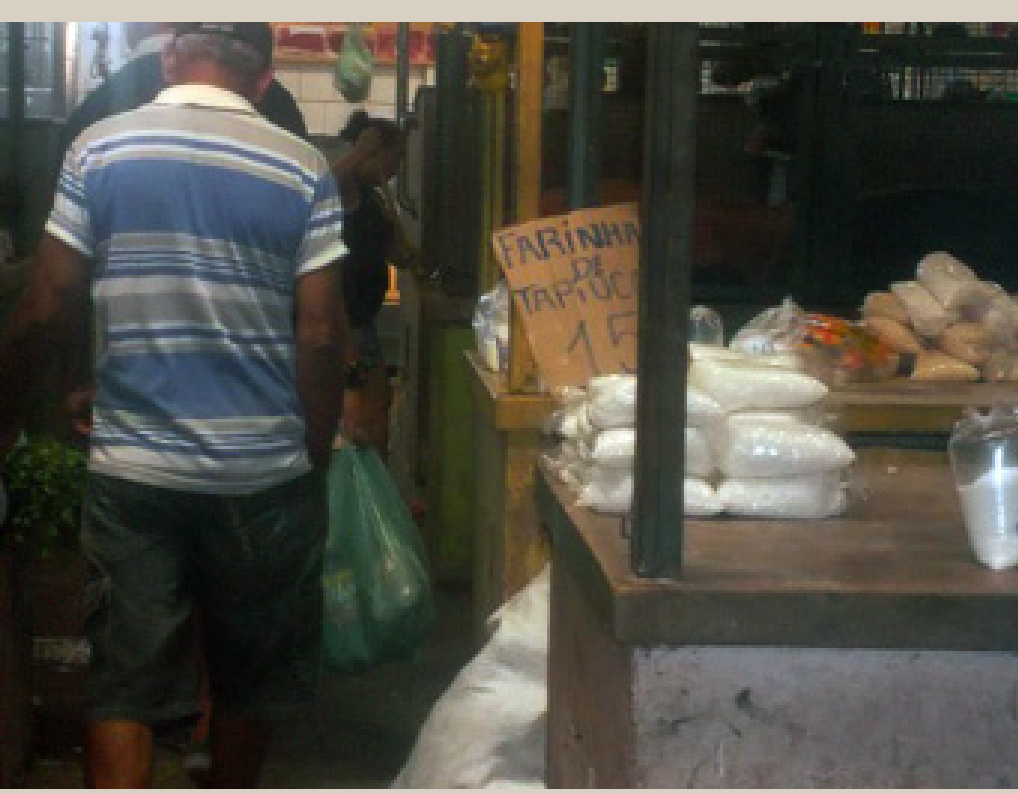

Fonte: Elaborada pelo autor. peixeiro tende a perceber qual a forma em que o cliente quer o peixe, isso pode se traduzir como o desenvolvimento do fator sensível. Do mesmo modo, o vendedor de legumes, ao colocá-los em um saco de plástico e expô-los para a venda, pontua a estrutura de percepção dos feirantes como maneira para obter a melhor venda e, consequentemente, maior atuação na dimensão estética sensível territorial.

Ainda que uma feira, não importa qual ela seja materialmente falando, não tenha surgido de um encontro fortuito -inesperado, ou provindo de uma colisão, tenha, ao contrário, nascido da necessidade expressa de um encontro, de uma troca; sua formação e os elementos que a sustentam e que, ao mesmo tempo, são sustentados por ela - o feirante, a freguesia, suas barracas, 
boxes, ambulantes, camelôs, dentre outros - reverberam nesse espaço, provocando "encontros fortuitos", gerando sentidos sem fim, emuladores de formas, gestando um mundo em si, na própria feira e no seu entorno. (CASTRO, 2013, p. 33)

Os emuladores de formas são característicos do próprio grau de venda entre o feirante e o freguês, na relação da expressividade, assim como também no envolvimento da prática, na movimentação e na valorização simbólica existentes na localidade. A estrutura do espaço em seu entorno condiciona a forma de atuação temporal simbólica que a feira possui, dentro do território sensivel que significa os "processos que se produzem e aparecem nas multiplicidades" (DELEUZE; CUATTARI, 1995, 'p. 8), em uma espécie de cartografia espacial múltipla. A diversidade de produtos à venda, como roupas, sapatos, geladeiras, camas, colocados em diferentes locais, no entorno da feira, é perceptível. Como se a realidade e a expressividade pudessem ocasionar influência simbólica, instituindo um processo de formatação da realidade então vivenciada em certa construção e envolvimento entre sujeitos.

É importante pensar em "fazer a leitura do social desde o desejo, fazer a passagem do desejo ao político, nos quadros dos modos de subjetivação" (GUATTARI; ROLNIK, 1986, p.16), sendo esta a base para a produtividade e consequência para o entendimento da relação existente no local.

É possível observar que o desejo também fica evidente na maneira de pensar, como, por exemplo, quando uma feirante escolhe alguém para uma tarefa, o faz com aquele que tem maior proximidade, como podemos inferir nesta fala: "A Lucir e a Ladecir, por afinidade por ficar bem" (COSTA, 2017) ${ }^{2}$, induzindo ao pensamento que de, alguma maneira, o desejo e a afinidade evidenciam o grau de poder simbólico político.

Neste momento, ressalta-se que a dimensão territorial sensível formata e institui a percepção de certo tempo de interpretação, da maneira como se condiciona a situação para o envolvimento e ligação entre sujeitos: "a sociedade não é uma substância concreta, mas um processo associação, isto é, um processo contínuo e criador de interações" (VANDENBERGUE, 2005, p. 77). Isso compõe o entendimento interacional entre indivíduos que envolvem grupos, que se percebem em experiências sensíveis de sentir em comum.

2 Catalina da Costa é vendedora de frutas como cupuaçu, bacuri, pupunha, biribá, banana, melão. Muitos dos produtos que ela vende são típicos da Amazônia. 
Imagem 4 - Movimentação no entorno da feira do Cuamá. Belém - PA (2017)

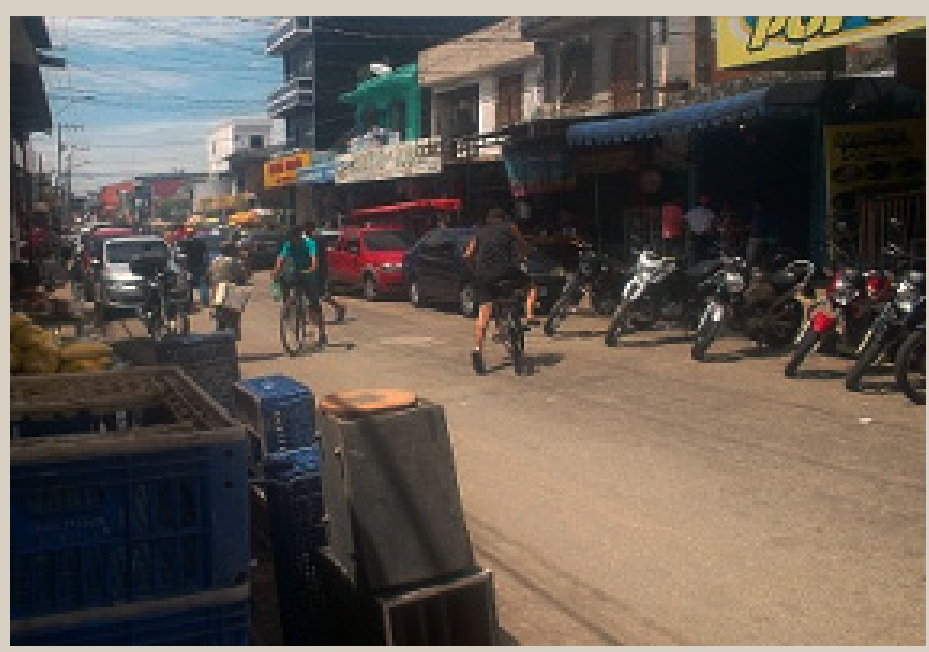

Fonte: Elaborada pelo autor
A comunicação está evidente no processo de formatação da realidade da vivência das pessoas que estão frequentando a feira. Porquanto, em diferentes dias, o processo se repete e se constrói como modo de apropriação do envolvimento simbólico interacional.

Aquilo que é contrário ao processo então vigente naquela localidade, ocasiona conflito. Como exemplo, é possível observar as reformas pelas quais a feira passou, ao longo de sua existência, em sua multiplicidade de vivência. Alguns feirantes lembram como foi impactante ter mudado de

lugar para se posicionar de outra maneira, como uma espécie de desterritorialização:

O território pode se desterritorializar, isto é, abrir-se, engajar-se em linhas de fuga e até sair do seu curso e se destruir. A espécie humana está mergulhada num imenso movimento de desterritorialização, no sentido de que seus territórios "originais" se desfazem ininterruptamente com a divisão social do trabalho, com a ação dos deuses universais que ultrapassam os quadros da tribo e da etnia, com os sistemas maquínicos que a levam a atravessar, cada vez mais rapidamente, as estratificações materiais e mentais (CUATTARI; ROLNIK, 1986, p. 323).

Pondera-se se aquela atitude de mudança ocasionou outra perspectiva de interação ou se pode ter sido um diferente modo de adequação com relação ao outro. O movimento de desterritorialização se conforma como um aspecto circundante de influência simbólica, o qual desencadeia processos de formatação temporal da realidade. A materialização da estratificação de mentalidades colabora para a prática, movimento e composição estética que ali é expresso.

A temporalidade, em conjunto com o espaço, com o universo simbólico, com as interações é parte do processo de multiplicidades de territórios que associam uma série de desterritorializações. Então, conjuntamente, formata a composição da própria caracterização do que a feira é, como podemos perceber na divisão dos boxes, no cheiro, no falatório, na sonoridade, nas cores, nos preços, na aproximação de fregueses, na roupa do feirante, nas vendas.

Todavia, é perceptível que se constitui como fonte de agregação para o movimento contínuo que se encontra na composição do real formado. A multiplicidade de sentido expresso cons- 
Imagem 5 - Venda de roupa. Belém - PA (2017)

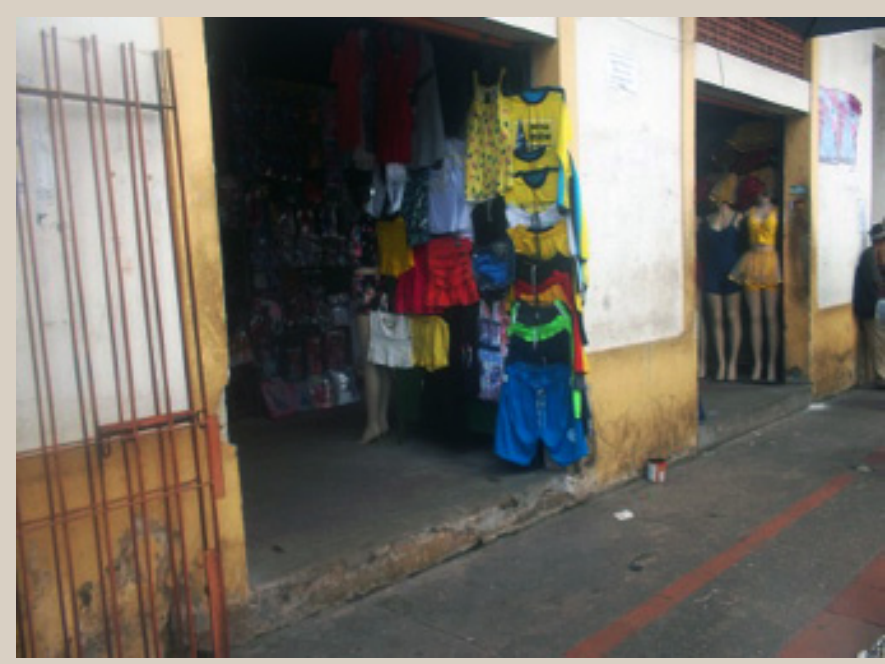

Fonte: Elaborada pelo autor. trói afinidade e facilidade para quem esta dentro da mesma frequência de sentido, ultrapassando a localidade, como é o caso da compra de mercadorias nas Centrais de Abastecimento do Pará (CEASA), da aproximação de pessoas de outros bairros e do procedimento de venda no entorno da localidade.

A passagem de experiência como modo de estruturar a divisão do trabalho é um fator importante, que possibilita pensar a desterritorialização, como se a mesma estivesse em base, o fator temporal então

composto de estruturas estéticas territoriais. Esse processo possui função de moldar mentalidades, estratificações no cotidiano.

Foi observado no local que os feirantes, que têm maior idade, passam para os filhos o ofício da venda, como forma de adequação para prosseguir o movimento, dentro da estrutura da realidade que é evidenciada. Nesse sentido, os descendentes continuam na passagem de certa memória que muitas vezes os seus antepassados idealizaram, no desenvolvimento do ofício da venda. Pode-se observar que a composição territorial se desterritorializa, desenvolve e forma outros processos de composição da interação, então expressa na localidade em sua diversidade cultural.

A dimensão sensível territorial encadeia-se por processos múltiplos, sentidos muitas vezes, visto que estão relacionados à comunicação, interação, o sentir-junto com outro em certo tempo. Sendo assim, nota-se que a desterritorialização constrói, como processo de continuidade simbólica, o que se expressa nas estruturas que a feira expressa na composição do real.

Temos como perspectiva, a noção da dimensão territorial estética, a sua abrangência para variadas estruturas. A feira insere-se em uma reprodução localizada, territorial e esteticamente, como algo que paira e possui abrangência em diferentes modos. Compara-se a relação do local com o global de forma condicionada, dentro de diferentes processos interacionais que se desenvolvem na qualidade da memória dos frequentadores, que ali interagem quanto à produção territorial da realidade então formada. 
A estética na composição política e econômica, no sentido amplo da percepção do território, é relevante para o entendimento da complexidade do que ali pode ser formatado dentro do fator sensível.

A política (referida às relações espaço-poder em geral) ou jurídico-política (relativa também a todas as relações espaço-poder institucionalizadas): a mais difundida, onde o território é visto como um espaço delimitado e controlado, através do qual se exerce um determinado poder, na maioria das vezes - mas não exclusivamente-relacionado ao poder político do Estado. Cultural (muitas vezes culturalista) ou simbólico-cultural: prioriza a dimensão simbólica e mais subjetiva, em que o território é visto, sobretudo, como o produto da apropriação/valorização simbólica de um grupo em relação ao seu espaço vivido. Econômica (muitas vezes economicista): menos difundida, enfatiza a dimensão espacial das relações econômicas, o território como fonte de recursos e/ou incorporado no embate. (HAESBAERT, 2007, p. 40)

A composição política tem como ordem principal as relações espaço-poder que se generalizam em diferentes estruturas estéticas dentro da composição social, como fonte de apropriação territorial e de construção, manutenção ou desconstrução de poder. Notamos que aquilo que se encontra de maneira localizada na feira pode ser reverberado para outras dimensões de realidade temporal, envolvida na mentalidade situacional humana dos sujeitos ali existente.

A composição econômica, que enfatiza a dimensão espacial das relações econômicas, sendo perceptível o território como recurso, pode ser simbólica ou até mesmo uma situação de ausência de construção e desterritorialização. A multiplicidade político-econômica aprofunda-se e formata variadas fontes de poder simbólico, então desenvolvidas no local.

A economia que aqui estamos expressando não é aquela apenas de venda do procedimento de troca de dinheiro por produto, mas aquela que se condiciona dentro do fator simbólico. É como se ocorresse ordenamento dentro de suportes de construção do que é evidenciado na feira, agregando o desenvolvimento de alguma natureza emocional, formando poderio imagético simbólico sensível.

Desta forma, observamos que a formatação do real ali desenvolvida recebe influência da expressão e essência do ser amazônico, dentro de diferentes ordens simbólicas de sensibilidade temporal. A dimensão sensível territorial efetua-se em diferentes direções e por várias camadas de realidades expressas no cotidiano da localidade, no seu processo de construção e identificação com o outro, assim como na evidência da composição territorial, tendo como base o sentir em comum que influencia as mentalidades e realidades ali existentes. 


\section{Considerações finais}

Pudemos constatar que, no espaço da feira do Guamá, a relação dos sujeitos frequentadores possui diversas construções, que colaboram para a reverberação das interações, na composição estética da identificação comunicacional e no desenvolvimento da sensibilidade territorial. A pesquisa propõe a possibilidade de percepção na diversidade existente na localidade, assim como expressividades para a condição da construção espacial temporal da realidade presente.

O aspecto lógico ou econômico possui justificativa para a movimentação do local. Todavia, não se pode deixar de lado a própria expressão que ali persiste. Assim, notamos a estrutura da vida social do cotidiano, como é percebido na movimentação da identificação e no aspecto territorial, modo vivente de sentir em comum a arte de viver.

Observamos que a estética da identificação comunicacional caracteriza-se na composição da construção de sensibilidade interacional, envolve emoções e segue a formatação da perspectiva real dos frequentadores. Um processo de instituição do movimento, caracterizada por um sentir em conjunto, ética da estética, possibilidade de uma arte generalizada.

A composição e o desenvolvimento da formatação e da sensibilidade territorial - envolvida e formada na capacidade que a localidade encontra, dentro de sua composição de tempo de construção real - formata diversas relações sociais, assim como desenvolve e envolve formas de relações culturais que se caracterizam como ponto norteador do que é expresso na feira.

Esta composição da estética da identidade comunicacional, assim como o processo territorial ratifica a interação que surge com quem frequenta a feira. A posição pela qual a interação e a comunicação se envolvem, propõe novos horizontes para o entendimento de algo que formata a realidade ali observada e impulsiona relações entre sujeitos em diversas escalas.

A feira do Guamá em sua diversidade cultural possui múltiplas características, que têm como base o desenvolvimento de identificações e aspectos territoriais, o sentido de ser, para a sua própria formatação real temporal à sensibilidade. A localidade expressa aspectos fundamentais da própria essência da sociedade amazônica e de sua composição, bem como sua importância para a formação de processos comunicativos universais e humanos. A nossa investigação tem como ponto principal trazer primeiras reflexões, para que possam fomentar debates e futuros estudos importantes dentro da temática de pesquisa aqui colocada. 


\section{Referências}

CASTRO, Marina; CASTRO, Fábio.No emaranhado do Guamá: trajetos etnográficos numa feira de Belém. Ponto urbe - revista do núcleo de antropologia urbana da USP, São Paulo, p. 3, v. 20, jun. 2017.

CASTRO, Fábio; XAVIER, Fábio; CASTRO, Marina. A dimensão èstética na feira do Cuamá, Belém - PA. Revista Vis: Revista do Programa de Pós-Graduação em Arte, Brasília, v. 16, n. 2, p. 363, jul. 2017.

CASTRO, Marina. A arte na sua cotidianidade: Uma percepção de arte na feira do Cuamá. 2013. 154 f. Dissertação (Mestrado em Arte) - Universidade Federal do Pará, Belém, 2013.

COSTA, Catalina. Catalina da Costa: entrevista 2 [dez. 2017]. Entrevistador: Fábio Rodrigo de Moraes Xavier. Cravador de voz (6 min).

COSTA, Fábio; ROCHA, Márcio. Geografia: conceitos e paradigmas - apontamentos preliminares. Revista de Ceografia, Meio Ambientee Ensino, Campo Mourão, v.1, n. 2, p. 25-56, 2010.

CUCHE, Denys. A noçãode cultura nas ciências sociais. Bauru: EDUSC, 1999.

DELEUZE, Gilles; GUATTARI, Félix. Mil Platôs: capitalismo e esquizofrenia, v. 1. Rio de Janeiro: Ed. 34, 1995.

FRIDMAN, Luis Carlos. Vertigens pós-modernas: configurações institucionais contemporâneas. Rio de Janeiro: Relume/Dumará, 2000.

CUATTARI, Félix; ROLNIK, Suely. Micropolítica: cartografias do desejo. Petrópolis: Vozes. 1986.

HAESBAERT, Rogério. Identidades Territoriais: entre a multiterritorialidade e a reclusão territorial (ou: do hibridismo cultural) à essencialização das identidades. In: ARAÚjO, Frederico Guilherme Bandeira de;

HAESBAERTH, Rogério (Orgs.). Identidades e Territórios: Questões e Olhares Contemporâneos. Rio de Janeiro: Access -Didáticos, 2007. p. 33-56.

HAESBAERTH, Rogério. Dos múltiplos territórios à multiterritorialidade. Porto Alegre, set. de 2004. Disponível em: $<$ http://w3.msh.univse2.fr/cdp/documents/ CONFERENCE Rogério Haesbaert. pdfs. Acesso em: 4 dez. 2017.

HALL, Stuart. A identidade.cultural na pós-modernidade. Rio de Janeiro: DPeA, 1999.

LOBATO, Flávio; CAÑETE, Voyner. Farinha de feira: memórias e identidades de vendedores em feiras do Bairro do Guamá, Belém (PA). Revista lluminuras, Porto Alegre, v. 16, n. 37, p. 242, 2015.

MAFFESOLI, Michel. Elogio da razão sensível. Petrópolis: Vozes, 1998. 
MAFFESOLI, Michel. No fundo das aparências. 2. ed. Petrópolis: Vozes, 1999.

OLIVEIRA, Mario. Mario de Oliveira: entrevista 1 [dez. 2017]. Entrevistador: Fábio Rodrigo de Moraes Xavier. Gravador de voz (6 min).

SCHUTZ, Alfred. Sobre a fenomenologia e relações sociais. Petrópolis: Vozes, 2012.

VANDENBERGUE, Frederic. As sociologias de Georg Simmel. Belém: Ed. Universitária UFPA, 2005.

Recebido em: 25 de agosto de 2018 Aprovado em: 12 de abril de 2019 